\title{
The Role of Renal Resistive Index in Assessment of Functional Renal Impairment in Patients with Liver Cirrhosis
}

\author{
Ayman Mohamed EL-Lehleh ${ }^{l}$, Naglaa Said Mohamed El Abd ${ }^{l}$, \\ Shaimaa Abd El Hamid Abd El Mageed ${ }^{2}$, Randa Mohamed Sadiek ${ }^{1}$ \\ ${ }^{I}$ Tropical Medicine Department, Faculty of Medicine, Menoufia University, Menoufia, Egypt \\ ${ }^{2}$ Diagnostic Radiology Department, Faculty of Medicine, Menoufia University, Menoufia, Egypt
}

Corresponding Author Naglaa Said Mohamed El-Abd

Mobile: 01092304322

E mail:

Naglaa_elabd@yahoo. com

Key words: Functional renal impairment, Liver cirrhosis, renal resistive index
Background and study aim: Renal dysfunction often develops in patients with liver cirrhosis. Hepatorenal syndrome (HRS) represents the end-stage of reduction in renal perfusion. Duplex Doppler ultrasonography of the kidneys is a noninvasive method to assess blood flow and arterial vascular resistance as a parameter for vasoconstriction. This study aimed to assess the role of renal resistive index as a non-invasive marker for early detection of functional renal impairment in patients with liver cirrhosis.

Patients and Methods: This study was conducted on 20 patients with liver cirrhosis without ascites vs. 60 patients with liver cirrhosis and ascites and 20 healthy subjects as control group. Patients and control were subjected to complete blood picture, liver and kidney functions, serum electrolytes, twenty four hours urinary sodium, abdominal ultrasonography and duplex Doppler evaluation of the renal arteries with calculation of mean renal RI.

\section{INTRODUCTION}

Advanced liver cirrhosis is associated with poor clinical outcome. Therefore, assessment of prognosis is important in the management of these patients [1].

Renal dysfunction often develops in patients with liver cirrhosis. In its most severe form, this kidney dysfunction is termed the hepatorenal syndrome, which is one of many potential causes of acute kidney injury in patients with acute or chronic liver diseases. Affected patients usually have portal hypertension due to cirrhosis, but can also have fulminant hepatic failure from any cause [2].
Results: Highly significant difference between cirrhotic patients with ascites and cirrhotic patients without ascites and controls regarding mean renal resistive index for both kidneys $(\mathrm{P}<0.001)$. At Cutoff point of renal RI 0.71 , the sensitivity, specificity and accuracy to predict HRS were $100 \%, 80 \%$ and $82 \%$ respectively with AUC $=0.997$. A statistical high significant positive correlation between RI and serum creatinine, child class, MELD score and MELD-Na ( $\mathrm{r}=0.0 .818, \mathrm{r}=0.0 .539, \mathrm{r}=$ $0.739 \mathrm{r}=0.807$ respectively and $\mathrm{P}<0.001)$. A statistical high significant negative correlation between RI and serum sodium, 24 hours urinary sodium, and platelets $(\mathrm{r}=$ $-0.778, r=0 .-0.688, r=-0.422$ respectively and $\mathrm{P}<0.001)$.

Conclusion: Renal duplex Doppler ultrasound is useful as a non-invasive method for the evaluation of the renal hemodynamic changes in cirrhotic patients and can predict HRS.
Hepatorenal syndrome represents the end-stage of reduction in renal perfusion induced by increasingly severe hepatic injury [3]. Despite notable splanchnic arterial vasodilatation and hyperdynamic circulation, patients with cirrhosis show increased renal arterial tone, resulting in poor renal perfusion [4].

Decreased peripheral vascular resistance with activation of compensatory mechanisms [the sympathetic nervous system (SNS), renin-angiotensinaldosterone system (RAAS) and antidiuretic hormone (ADH)] leads to renal vasoconstriction [5]. 
In liver cirrhosis, serum creatinine is inaccurate in diagnosis of renal dysfunction as it overestimates renal function due to decreased creatinine production by the liver, protein calorie malnutrition and muscle wasting, therefore, better methods to diagnose this early stage of renal disease are needed [6].

Duplex Doppler ultrasonography of the kidneys is an easy and non-invasive method to assess blood flow and arterial vascular resistance as a parameter for vasoconstriction [7]. The arterial resistive index (RI) is the most widely used parameter to estimate the arteriolar vascular resistance. It is regularly used for screening of transplant rejection or to diagnose renal artery stenosis [8].

A positive correlation has been described between intrarenal RI and plasma renin activity as well as, plasma aldosteron concentration. The activation of the renin-angiotensin-aldosterone system plays an important role in the pathogenesis of hepatorenal syndrome [9]. The aim of the present work was to assess the role of renal resistive index as a non-invasive marker for early detection of functional renal impairment in patients with liver cirrhosis.

\section{PATIENTS AND METHODS}

This study was conducted on 80 patients with liver cirrhosis (proved by clinical examination, laboratory and radiological studies) and 20 healthy subjects without evidence of any liver or kidney disease as controls. Patients and controls were selected from the outpatient and/or inpatient Department of Tropical Medicine, Menoufia University hospital in the period between November 2015 to May 2016. Patients with renal impairment due to any cause other than hepatorenal syndrome, diabetes mellitus, hypertension, acute gastrointestinal bleeding and malignant diseases were excluded. Patients were 53 (66.25\%) males and $27(33.75 \%)$ females. Their ages ranged from 19 to 80 years with a mean age of $47.54 \pm 15.52$ as well as, 20 healthy persons of matched age and sex as a control group. This study was approved by the Committee for Ethics of Faculty of Medicine, Menoufia University, Egypt and written informed consent was obtained from each subject before blood was collected.

\section{Patients and controls were classified into the following groups:}

Group I: 20 patients with liver cirrhosis without ascites.

Group II: 60 patients with liver cirrhosis and ascites.
Group III: 20 healthy subjects as controls.

\section{All patients and controls were subjected to the} following:

- Proper and detailed history taking.

- Complete clinical examinations (general and local abdominal examinations).

- Laboratory investigations: Complete blood picture, random blood sugar, liver function tests includes [serum bilirubin, serum albumin, Alanin transaminase (ALT), Aspartate transaminase (AST), prothrombin time \& concentration and INR], renal function tests [blood urea and serum creatinine], serum electrolytes [serum sodium concentration and serum potassium concentration], urine analysis, twenty four hours urinary sodium and serological tests for viral markers [HBsAg by and HCVAb by ELISA].

- Child-Pugh classification was calculated for all studied patients to assess the severity of liver disease, depending on patients' clinical and laboratory data (ascites, hepatic encephalopathy, serum albumin, serum bilirubin and international normalized ratio INR [10]. MELD score and MELD-Na also were calculated for all studied patients according to the following formulae: MELD = 9.57 loge [Creatinine $(\mathrm{mg} / \mathrm{dL})]+3.78$ loge [Bilirubin $(\mathrm{mg} / \mathrm{dL})]+11.2$ loge [International Normalized Ratio] + 6.43 [11]. MELD-Na = MELD - Na - [0.025 X MELD X (140 - Na)] +140 [12].

- Radiological evaluation; Abdominal ultrasonography was done to evaluate liver, spleen, portal vein, the amount of ascites and both kidneys. According to the amount of ascites and the criteria for hepatorenal syndrome which include; liver cirrhosis with ascites, serum creatinine $>1.5 \mathrm{mg} / \mathrm{dL}$, no improvement of serum creatinine (a decrease in serum $<1.5 \mathrm{mg} / \mathrm{dL}$ ) after 2 days off diuretics and volume expansion with albumin $(1 \mathrm{~g} / \mathrm{kg}$ body weight up to a maximum of $100 \mathrm{~g} / \mathrm{d}$ ), absence of shock, no current or recent treatment with nephrotoxic drugs, absence of signs of parenchymal renal disease, as suggested by proteinuria $(>500 \mathrm{mg} / \mathrm{d}$ ) or haematuria ( $>50$ red blood cells per highpower field) and/or abnormal renal ultrasound [13], group II (cirrhotic patients with ascites) was subdivided into:

G IIa: 27 patients with mild to moderate ascites. G II b: 22 patients with massive ascites. G IIc: 11 patients with hepatorenal syndrome. 
- The renal Doppler US technique; patient fast for 8 hours prior to the Doppler ultrasonographic examination of the native kidney. The transducer was positioned so as to visualize the lateral or posterolateral aspect of the kidney. In this position, Doppler examination could performed with the lowest appropriate angle (0-60), establishing an appropriate approach toward vascular structures in the periphery of the hilum and permitting visualization of the kidney without obstruction by gases present in the segments of the intestine and causing artifact. The patient was placed in the decubitus or semi-decubitus position with the kidney to be examined on top, thus permitting visualization of the kidney and including an image of the abdominal aorta. The lateral tip of the transducer was angled slightly toward the caudal aspect, permitting appropriate imaging of the course of the main artery or vein [14].

- Doppler analysis; patients and controls underwent abdominal ultrasonography using US equipment with color Doppler capability using convex linear $(2.8-5 \mathrm{MHz})$ transducer (General electric LOGIQ P6 device). The renal resistive index was automatically calculated by the US equipment. Intra-renal resistance was measured on inter-lobar arteries three times in different regions of each kidney (upper, middle and lower poles) and then the mean value was calculated. Subsequently, a mean RI was calculated for each subject (mean of both kidneys) [15].

\section{Statistical Analysis}

Data was statistically analyzed using SPSS (statistical package for social science) (IBM, New York, USA) program version 22 for windows and for all the analysis a $\mathrm{p}$ value $<0.05$ was considered statistically significant.

\section{RESULTS}

\section{Demographics of the studied groups}

There was no statistical significant difference between studied groups as regards age and sex distribution ( $\mathrm{p}$ value $>0.05$ ). Cirrhotic patients without ascites (group I) were 14 males $(70 \%) \&$ 6 females $(30 \%)$ with their mean age $45.5 \pm 15.4$. Cirrhotic patients with ascites (group II) were 39 males $(65 \%)$ \& 21 females $(35 \%)$ with their mean age 51.6 \pm 15.5 . Control group (group III) were 12 males $(60 \%)$ and 8 females $(40 \%)$ with their mean age $50.4 \pm 16.3$.

There was a statistical significant difference between the cirrhotic patients without ascites and cirrhotic patients with ascites regarding history of hematemsis and/or melena, liver and splenic size ( $\mathrm{p}$ value $<0.05$ ) as well as, there was a statistical high significant difference between the same groups regarding jaundice, lower limb edema and history of hepatic encephalopathy ( $p$ value $<0.001$ ).

There was a statistical high significant difference between the studied groups regarding hemoglobin concentration and platelets count ( $p$ value $<0.001$ ) as well as there was a statistical significant difference between the studied groups regarding WBCs count ( $\mathrm{p}$ value $<0.05$ ). There was a statistical high significant decrease in the mean values of hemoglobin concentration $(10.10 \mathrm{gm} / \mathrm{dl})$, WBCs $(3.96 \times 103 / \mathrm{cm} 3)$ and platelet count $\left(70.8 \times 10^{3}\right.$ $/ \mathrm{cm}^{3}$ ) in cirrhotic patients with ascites in comparison with cirrhotic patients without ascites $\left(12.34 \mathrm{gm} / \mathrm{dl}, 6.04 \times 103 / \mathrm{cm} 3\right.$ and $159.2 \times 10^{3}$ $/ \mathrm{cm}^{3}$ respectively) and control group $(13.0 \mathrm{gm} / \mathrm{dl}$, $6.47 \times 10^{3} / \mathrm{cm}^{3}$ and $225.9 \times 10^{3} / \mathrm{cm}^{3}$ respectively).

There was a statistical high significant difference between the studied groups regarding total bilirubin, serum albumin, prothrombin concentration, AST and ALT ( $\mathrm{p}$ value $<0.001$ ). There was a statistical high significant increase in the mean values of serum bilirubin $(4.25 \mathrm{mg} / \mathrm{dl})$ as well as, a statistical high significant decrease in serum albumin (2.44 $\mathrm{gm} / \mathrm{dl}$ ) and prothrombin concentration (48.27\%) in cirrhotic patients with ascites in comparison with cirrhotic patients without ascites (1.04 $\mathrm{mg} / \mathrm{dl}, 3.98 \mathrm{gm} / \mathrm{dl}$ and $85.5 \%$ respectively) and control group $(0.69 \mathrm{mg} / \mathrm{dl}, 4.13 \mathrm{gm} / \mathrm{dl}$ and $98.8 \%$ respectively)

There was a statistical high significant difference between cirrhotic patients without ascites and cirrhotic patients with ascites regarding Child classification ( $\mathrm{p}$ value $<0.001$ ). Most patients in GI were Child A (18 patients, 90\%) on the other hand, the majority of patients in GII were Child C (49 patients, $81.7 \%$ ).

Regarding abdominal ultrasound findings among studied groups, there was a statistical high significant difference between the studied groups regarding size of liver and spleen, portal vein dilatation and the amount of ascites ( $\mathrm{p}$ value $<0.001)$. There was no statistical significant difference between the cirrhotic patients without ascites and cirrhotic patients with ascites regarding the etiology of liver cirrhosis ( $p$ value $=0.69$ ). Chronic HCV was the commonest etiology of cirrhosis in both groups. 
There was a statistical high significant difference between the studied groups regarding kidney function tests and serum $\mathrm{Na}$ ( $\mathrm{p}$ value < 0.001 ). There was a statistical high significant increase in blood urea and serum creatinine as well as, a statistical high significant decrease in serum $\mathrm{Na}$ in patients with massive ascites and patients with hepatorenal syndrome in comparison with other groups. Table (1)

Table (1): Kidney function tests and serum $\mathrm{Na}+$ among studied groups $(\mathrm{No}=100)$

\begin{tabular}{|c|c|c|c|c|c|c|c|}
\hline \multirow{3}{*}{$\begin{array}{l}\text { Studied } \\
\text { variable }\end{array}$} & \multirow{2}{*}{$\begin{array}{c}\text { GI } \\
(\mathbf{N}=\mathbf{2 0})\end{array}$} & \multicolumn{3}{|c|}{ GII $(N=60)$} & \multirow{2}{*}{$\begin{array}{c}\text { GIII } \\
(\mathrm{N}=\mathbf{2 0})\end{array}$} & \multirow{3}{*}{$\mathbf{K}$} & \multirow{3}{*}{$\begin{array}{c}P \\
\text { value }\end{array}$} \\
\hline & & $\begin{array}{c}\text { GIIa } \\
(\mathbf{N}=27)\end{array}$ & $\begin{array}{c}\text { GIIb } \\
(\mathbf{N}=\mathbf{2 2})\end{array}$ & $\begin{array}{c}\text { GIIc } \\
(\mathrm{N}=11)\end{array}$ & & & \\
\hline & $\overline{\mathrm{X}} \pm \mathrm{SD}$ & $\overline{\mathrm{X}} \pm \mathrm{SD}$ & $\overline{\mathrm{X}} \pm \mathrm{SD}$ & $\overline{\mathrm{X}} \pm \mathrm{SD}$ & $\overline{\mathrm{X}} \pm \mathrm{SD}$ & & \\
\hline $\begin{array}{l}\text { Blood urea } \\
\text { Range }\end{array}$ & $\begin{array}{c}28.9 \pm 4.58 \\
21-38 \\
\end{array}$ & $\begin{array}{c}27.0 \pm 3.80 \\
21-35\end{array}$ & $\begin{array}{c}39.5 \pm 12.6 \\
23-89\end{array}$ & $\begin{array}{c}78.6 \pm 18.3 \\
38-105\end{array}$ & $\begin{array}{c}26.8 \pm 4.20 \\
21-34\end{array}$ & 47.1 & 0.001 \\
\hline $\begin{array}{l}\text { S. creatinine } \\
\text { Range }\end{array}$ & $\begin{array}{r}0.82 \pm 0.30 \\
0.30-1.30 \\
\end{array}$ & \begin{tabular}{|c|}
$0.73 \pm 0.27$ \\
$0.30-1.20$ \\
\end{tabular} & $\begin{array}{c}1.40 \pm 0.70 \\
0.40-4.20\end{array}$ & $\begin{array}{c}3.02 \pm 0.65 \\
2.30-4.50 \\
\end{array}$ & $\begin{array}{c}0.73 \pm 0.83 \\
0.30-1.20 \\
\end{array}$ & 46.1 & 0.001 \\
\hline Serum Na & $139 \pm 3.22$ & $136.5 \pm 5.57$ & $129.1 \pm 5.57$ & $116.7 \pm 6.37$ & $139.1 \pm 3.22$ & 52.1 & 0.001 \\
\hline
\end{tabular}

There was a statistical high significant difference between the studied groups regarding MELD and MELD-Na scores ( $p$ value $<0.001)$. There was high significant increase in MELD and MELD-NA scores in patients with massive ascites and patients with hepatorenal syndrome in comparison with other groups as well as when compared with each other, however there was no statistical significant difference between cirrhotic patients without ascites (GI) and cirrhotic patients with mild to moderate ascites (GIIa). Table (2)
There was a statistical high significant difference between the studied groups regarding 24 hour urine output and 24 hour urinary $\mathrm{Na}$ ( $\mathrm{p}$ value < 0.001 ). There was a significant decrease in 24 hour urinary $\mathrm{Na}$ in cirrhotic patients with massive ascites and patients with hepatorenal syndrome in comparison with other groups, however there was no statistical significant difference between cirrhotic patients with mild to moderate ascites (GIIa) and cirrhotic patients with massive ascites (GIIb). Table (2) 
Table (2): MELD and MELD-Na score among patients in GI and GII (NO=80)

\begin{tabular}{|c|c|c|c|c|c|c|c|}
\hline \multirow{3}{*}{$\begin{array}{c}\text { Studied } \\
\text { variables }\end{array}$} & \multirow{3}{*}{$\begin{array}{c}\begin{array}{c}\text { GI } \\
(\mathbf{N}=20)\end{array} \\
\overline{\mathrm{X}} \pm \mathrm{SD}\end{array}$} & \multicolumn{3}{|c|}{ GII $(N=60)$} & \multirow{3}{*}{$\mathbf{F}$} & \multirow{3}{*}{$\begin{array}{c}P \\
\text { value }\end{array}$} & \multirow{3}{*}{$\begin{array}{c}\text { Post hoc } \\
\text { test }\end{array}$} \\
\hline & & $\begin{array}{c}\text { GIIa } \\
(\mathbf{N}=27)\end{array}$ & $\begin{array}{c}\text { GIIb } \\
(\mathrm{N}=\mathbf{2 2})\end{array}$ & $\begin{array}{c}\text { GIIc } \\
(\mathrm{N}=11)\end{array}$ & & & \\
\hline & & $\overline{\mathrm{X}} \pm \mathrm{SD}$ & $\overline{\mathrm{X}} \pm \mathrm{SD}$ & $\overline{\mathrm{X}} \pm \mathrm{SD}$ & & & \\
\hline MELD score & $9.79 \pm 0.73$ & $10.1 \pm 0.98$ & $11.2 \pm 1.21$ & $13.3 \pm 0.99$ & 36.7 & 0.001 & $\begin{array}{c}\mathrm{P} 1: 0.323 \\
\text { P2: }<0.001 * * \\
\text { P3:0.001** } \\
\text { P4: }<0.001 * * \\
\text { P5:<0.001** } \\
\text { P6: }<0.001 * *\end{array}$ \\
\hline $\begin{array}{l}\text { MELD-Na } \\
\text { score }\end{array}$ & $10.6 \pm 2.51$ & $12.7 \pm 4.30$ & $18.9 \pm 4.59$ & $28.8 \pm 4.41$ & 59.1 & 0.001 & $\begin{array}{c}\mathrm{P} 1: 0.079 \\
\mathrm{P} 2:<0.001^{* *} \\
\mathrm{P} 3: 0.001^{* *} \\
\mathrm{P} 4:<0.001^{* *} \\
\mathrm{P} 5:<0.001^{* *} \\
\mathrm{P} 6:<0.001^{* *}\end{array}$ \\
\hline $24 \mathrm{hr}$ urinary $\mathrm{Na}$ & $79.0 \pm 33.6$ & $55.2 \pm 24.9$ & $46.7 \pm 20.89$ & $9.30 \pm 6.53$ & 35.6 & 0.001 & $\begin{array}{c}\text { P1:0.007 } \\
\text { P2: }<0.001 * * \\
\text { P3:0.001** } \\
\text { P4:0.061 } \\
\text { P5: }<0.001^{* *} \\
\text { P6: }<0.001^{* *}\end{array}$ \\
\hline
\end{tabular}

** highly significant

P1:between GI and GIIa , P2:between GI and GIIb , P3:between GI and GIIc , P4:between GIIa and GIIb , P5:between GIIa and GIIc , P6:between GIIb and GIIc

There was a statistical high significant difference between the studied groups regarding renal resistive index ( $\mathrm{p}$ value $<0.001)$. In this study, the mean renal resistive index was significantly higher in all cirrhotic patients groups (GI and GII a,b,c) than in control group. There was a statistical high significant increase in resistive index in patients with massive ascites and patients with hepatorenal syndrome in comparison with other groups. On the other hand, there was no statistical significant difference between cirrhotic patients without ascites and cirrhotic patients with mild to moderate ascites (Table $3)$. 
Table (3): Renal resistive index among studied groups (No=100)

\begin{tabular}{|c|c|c|c|c|c|c|c|c|}
\hline \multirow{3}{*}{$\begin{array}{l}\text { Renal } \\
\text { duplex }\end{array}$} & \multirow{2}{*}{$\begin{array}{c}\text { GI } \\
(\mathbf{N}=\mathbf{2 0})\end{array}$} & \multicolumn{3}{|c|}{ GII $(N=60)$} & \multirow{3}{*}{$\begin{array}{c}\text { GIII } \\
(\mathbf{N}=\mathbf{2 0})\end{array}$} & \multirow{3}{*}{$\mathbf{F}$} & \multirow{3}{*}{$\begin{array}{c}\mathbf{P} \\
\text { valu } \\
\mathbf{e}\end{array}$} & \multirow{3}{*}{ Post hoc test } \\
\hline & & $\begin{array}{c}\text { GIIa } \\
(\mathbf{N}=\mathbf{2 7}) \\
\end{array}$ & $\begin{array}{c}\text { GIIb } \\
(\mathrm{N}=22) \\
\end{array}$ & $\begin{array}{c}\text { GIIc } \\
(\mathrm{N}=11)\end{array}$ & & & & \\
\hline & $\overline{\mathrm{X}} \pm \mathrm{SD}$ & $\overline{\mathrm{X}} \pm$ SD & $\overline{\mathrm{X}} \pm$ SD & $\overline{\mathrm{x}} \pm$ SD & & & & \\
\hline Right & $\begin{array}{c}0.62 \pm 0.0 \\
7\end{array}$ & $\begin{array}{c}0.64 \pm 0.0 \\
3\end{array}$ & $\begin{array}{c}0.71 \pm 0.0 \\
3\end{array}$ & $\begin{array}{c}0.83 \pm 0.0 \\
4\end{array}$ & $\begin{array}{c}0.59 \pm 0.0 \\
1\end{array}$ & 79.5 & 0.001 & $\begin{array}{c}\mathrm{P} 1:<0.001^{* *} \\
\mathrm{P} 2<: 0.001^{* *} \\
\mathrm{P} 3:<0.001^{*} * \\
\mathrm{P} 4<: 0.001^{*} \\
\mathrm{P} 5:>0.05 \\
\mathrm{P} 6:<0.001^{* *} \\
\mathrm{P} 7:<0.001^{* *} \\
\mathrm{P} 8<: 0.001^{*} \\
\mathrm{P} 9:<0.001^{* *} \\
\mathrm{P} 10:<0.001^{*} \\
*\end{array}$ \\
\hline Left & $\begin{array}{c}0.63 \pm 0.0 \\
2\end{array}$ & $\begin{array}{c}0.65 \pm 0.0 \\
2\end{array}$ & $\begin{array}{c}0.73 \pm 0.0 \\
5\end{array}$ & $\begin{array}{c}0.84 \pm 0.0 \\
2\end{array}$ & $\begin{array}{c}0.61 \pm 0.0 \\
1\end{array}$ & $\begin{array}{c}281 . \\
7\end{array}$ & 0.001 & $\begin{array}{c}\text { P1: }<0.05^{*} \\
\text { P2: }<0.05^{*} \\
\text { P3:0.001** } \\
\text { P4: }<0.001^{* *} \\
\text { P5: }>0.05 \\
\text { P6: }<0.001^{* *} \\
\text { P7: }<0.001^{* *} \\
\text { P8: }<0.001^{*} \\
\text { P9: }<0.001^{* *} \\
\text { P10: }<0.001^{*} \\
*\end{array}$ \\
\hline $\begin{array}{l}\text { Mean } \\
\text { resistiv } \\
\text { e index } \\
\text { for both } \\
\text { kidneys }\end{array}$ & $\begin{array}{c}0.62 \pm 0.0 \\
1\end{array}$ & $\begin{array}{c}0.64 \pm 0.0 \\
3\end{array}$ & $\begin{array}{c}0.71 \pm 0.0 \\
4\end{array}$ & $\begin{array}{l}0.83 \pm 0.0 \\
3\end{array}$ & $\begin{array}{l}0.59 \pm 0.0 \\
1\end{array}$ & $\begin{array}{l}151 . \\
3\end{array}$ & 0.001 & $\begin{array}{c}\mathrm{P} 1:<0.001^{* *} \\
\mathrm{P} 2:<0.001^{* *} \\
\mathrm{P} 3:<0.001^{* *} \\
\mathrm{P} 4:<0.001^{*} \\
\mathrm{P} 5:>0.05 \\
\mathrm{P} 6:<0.001^{* *} \\
\mathrm{P} 7:<0.001^{* *} \\
\mathrm{P} 8:<0.001^{*} \\
\mathrm{P} 9:<0.001^{* *} \\
\mathrm{P} 10: 0.001^{* *}\end{array}$ \\
\hline
\end{tabular}

*Significant ** highly significant $\mathrm{F}$ : ANOVA test P1:between GIII and GI , P2:between GIII and GIIa, P3:between GIII and GIIb , P4:between GIII and GIIc , P5:between GI and GIIa, P6:between GI and GIIb , P7:between GI and GIIc , P8:between GIIa and GIIb , P9:between GIIa and GIIc , P10:between GIIb and GIIc

There was a statistical high significant positive correlation between renal resistive index and child score $(r=0.539)$, age $(r=0.226)$, total bilirubin $(r=0.678)$, blood urea $(r=0.815)$, serum creatinine $(\mathrm{r}=0.818)$, MELD score $(\mathrm{r}=$ $0.739)$ and MELD-NA score $(r=0.807)$ and there was a statistical high significant negative correlation between RI and serum albumin ( $\mathrm{r}=$ -0.621), prothrombin concentration $(\mathrm{r}=$ $0.535)$, platelets count $(\mathrm{r}=-0.422)$, serum sodium $(\mathrm{r}=-0.778), 24$ hours urinary sodium $(\mathrm{r}=-0.688)$. Table (4). Figure. $(1 \mathrm{a} \& \mathrm{~b})$. Figure. $(2 \mathrm{a} \& \mathrm{~b})$. 
Table (4): Correlation between renal resistive index and different variables among studied patients

\begin{tabular}{|l|c|c|}
\hline \multirow{2}{*}{\multicolumn{1}{c|}{ Studied variables }} & \multicolumn{2}{c|}{ Resistive index } \\
\cline { 2 - 3 } & r & P value \\
\hline CHILD classification & 0.539 & $0.001^{* *}$ \\
\hline Age & 0.226 & $0.043^{*}$ \\
\hline Serum albumin & -0.621 & $0.001^{* *}$ \\
\hline Prothrombin concentration & -0.535 & $0.001^{* *}$ \\
\hline Bilirubin & 0.678 & $0.001^{* *}$ \\
\hline Platelets count & -0.422 & $0.001^{* *}$ \\
\hline Serum Na & -0.778 & $0.001^{* *}$ \\
\hline 24hr Urinary Na & -0.688 & $0.001^{* *}$ \\
\hline Blood urea & 0.815 & $0.001^{* *}$ \\
\hline Serum creatinine & 0.818 & $0.001^{* *}$ \\
\hline MELD score & 0.739 & $0.001^{* *}$ \\
\hline MELD-Na & 0.807 & $0.001^{* *}$ \\
\hline
\end{tabular}
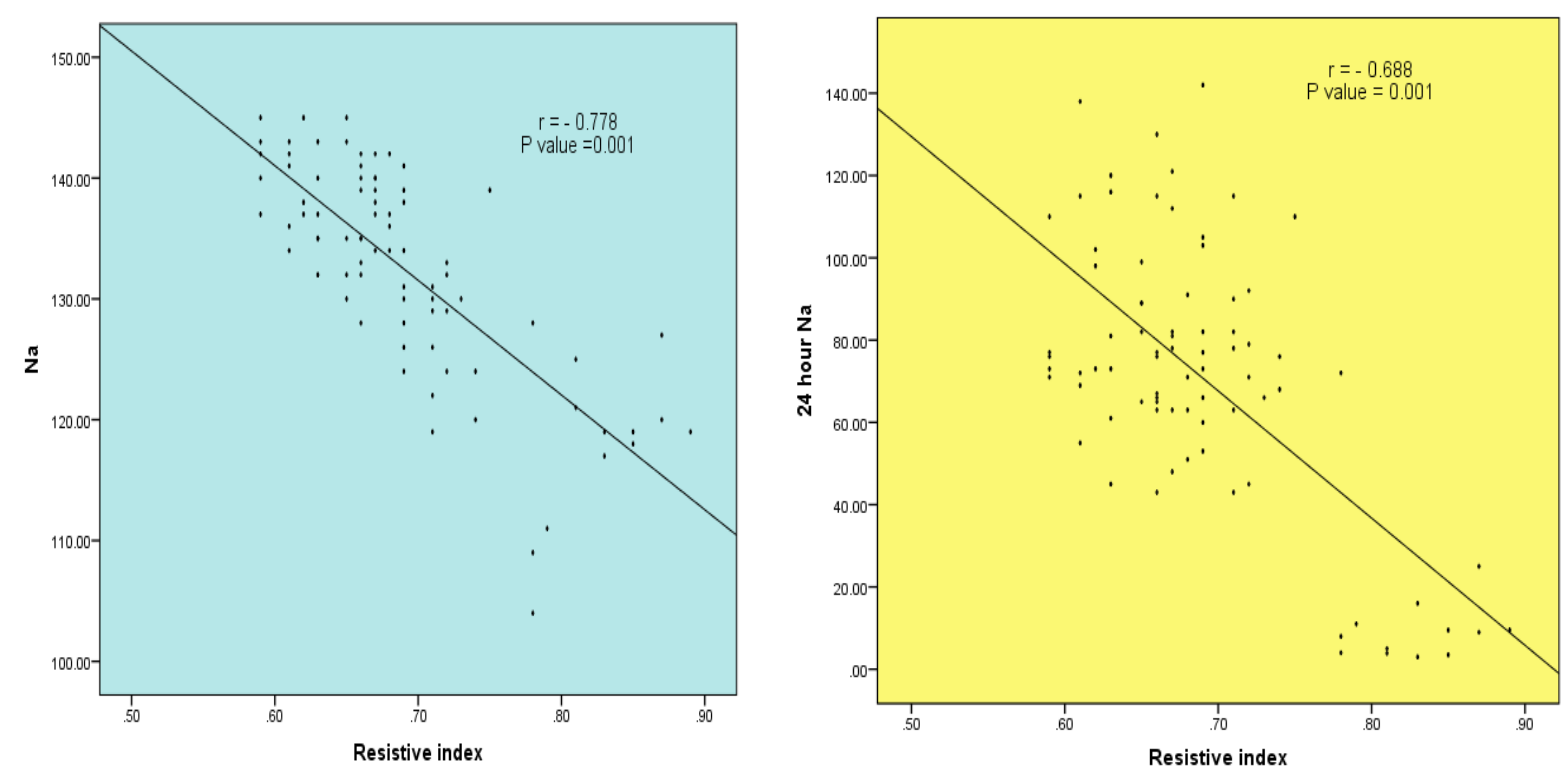

Fig. (1a\&b): Correlation between renal resistive index and Serum Na+ \&24hr Urinary Na among patients in GI and GII 

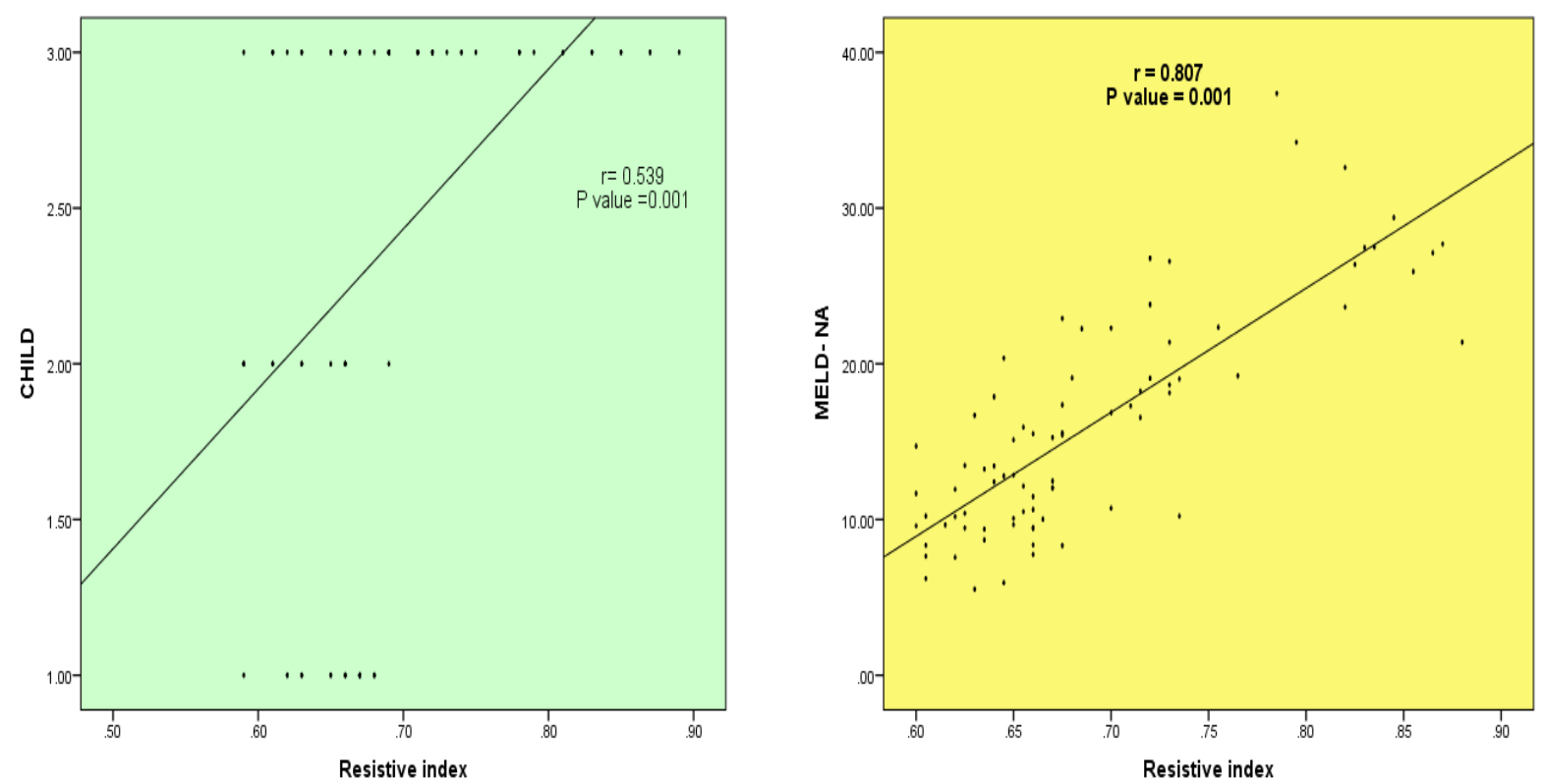

(Fig. 2 a\&b): Correlation between renal resistive index and CHILD\& MELD-Na score among patients in GI and GII

At Cutoff point of renal RI 0.71, the sensitivity of the test to predict hepatorenal syndrome was $100 \%$, the specificity was $80 \%$, PPV was
$44 \%$, NPV was $100 \%$, accuracy was $82 \%$ and $\mathrm{AUC}=0.997$. Figure (3).

\begin{tabular}{|c|c|c|c|c|c|}
\hline $\begin{array}{c}\text { Cutoff } \\
\text { point }\end{array}$ & Sensitivity \% & Specificity \% & $\begin{array}{c}\text { Positive } \\
\text { predictive } \\
\text { value\% }\end{array}$ & $\begin{array}{c}\text { Negative } \\
\text { predictive } \\
\text { value\% }\end{array}$ & $\begin{array}{c}\text { Diagnostic } \\
\text { accuracy\% }\end{array}$ \\
\hline 0.71 & 100 & 80 & 44 & 100 & 82 \\
\hline
\end{tabular}

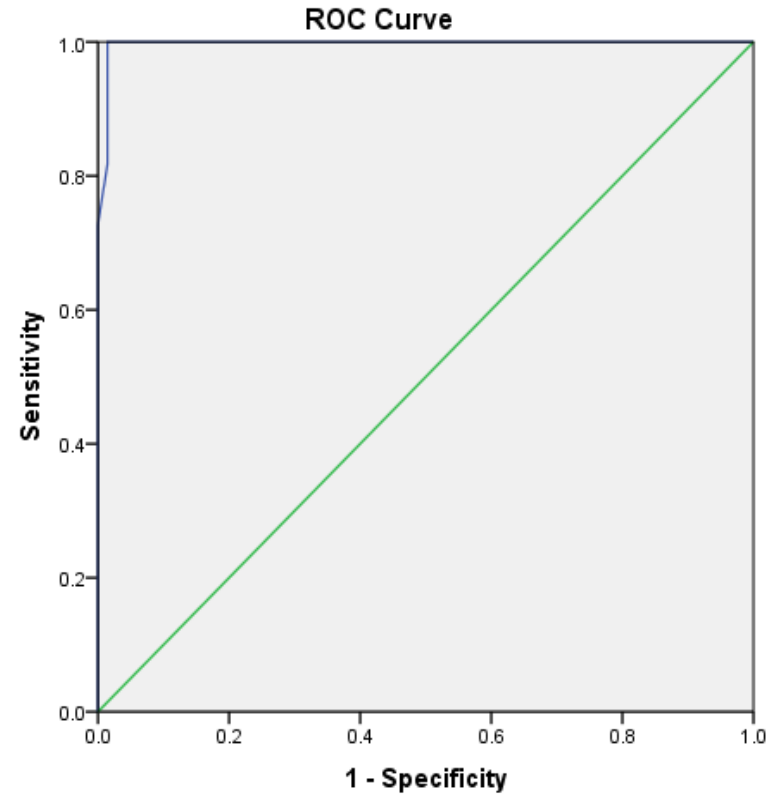

(Fig. 3): Renal resistive index ROC curve 


\section{DISCUSSION}

Cirrhosis is an increasing cause of morbidity and mortality in more developed countries. It is the 14th most common cause of death in adults worldwide but the fourth in central Europe; it results in 1.03 million deaths per year worldwide [16]. Renal dysfunction frequently complicates the clinical course of advanced liver disease and is invariably associated with poor clinical outcomes. So, optimal management of renal dysfunction in cirrhosis is extremely important. Renal dysfunction in chronic liver disease is characterized by impaired natriuresis, decreased free water clearance, and decreased glomerular filtration rate (GFR). Hyponatremia, ascites and hepatorenal syndrome (HRS) represent the clinical consequences of disturbances in renal functions [17]. Despite notable splanchnic arterial vasodilatation and hyperdynamic circulation, patients with cirrhosis show increased renal arterial tone, resulting in poor renal perfusion. Decreased peripheral vascular resistance with activation of compensatory mechanisms [the sympathetic nervous system (SNS), renin-angiotensin-aldosterone system (RAAS) and antidiuretic hormone (ADH)] leads to renal vasoconstriction [5].The intra-renal resistive index (RI) is the most frequently used parameter to assess intra-renal resistance and is calculated based on intra-renal duplex Doppler ultrasound measurements [18].

In this study the statistical analysis revealed no significant difference between the studied groups as regards age and sex distribution, this ensures that the demographic data has no effect on the results of the study indicating no bias in it.

Regarding liver function tests, there was a statistical high significant difference between the studied groups regarding total bilirubin, serum albumin, prothrombin concentration, AST and ALT. These results were in agreement with those reported by Goyal et al. [19] who stated that, there were significant differences in prothrombin concentration, AST, ALT, serum albumin and serum bilirubin between cirrhotic patients without ascites and cirrhotic patients with ascites. Also, Fouad et al. [20] reported that, prothrombin concentration and serum albumin were significantly higher while, serum bilirubin was significantly lower in patients with compensated liver cirrhosis than patients with decompensated cirrhosis and patients with hepatorenal syndrome.

In this study, there was no statistical significant difference between the cirrhotic patients without ascites and cirrhotic patients with ascites regarding the etiology of liver cirrhosis. Chronic $\mathrm{HCV}$ was the commonest etiology of cirrhosis in both groups (95\%) in GI and (91.7\%) in GII. This result agreed with the study done by Amer et al. [21] who reported that, the prevalence of $\mathrm{HCV}$ infection in Egypt is the highest reported worldwide of $14.7 \%$ and about $85 \%$ of those infected with HCV will develop chronic hepatitis of varying severity, nearly $20 \%$ of patients develop cirrhosis in 10-20 years.

Regarding the blood urea and serum creatinine, this study detected that, there was a statistical high significant difference between the studied groups ( $p$ value <0.001). There was a high significant increase in blood urea and serum creatinine in patients with massive ascites and patients with hepatorenal syndrome in comparison with other groups while, there was no statistical significant difference between cirrhotic patients without ascites and both control and cirrhotic patients with mild to moderate ascites. In agreement with this result, the study done by Nix et al. [22] who determined that, serum creatinine and blood urea levels in patients with the hepatorenal syndrome was significantly higher than that of other different groups $(p<0.05)$ but there was no significant changes in creatinine levels between cirrhotic patients without ascites and control group. While, creatinine levels in cirrhotic patients with ascites was higher than that in cirrhotic patients without ascites.

In the present study, there was a statistical high significant difference between studied groups as regards serum sodium levels and there was highly significant decrease in serum sodium in patients with massive ascites and patients with hepatorenal syndrome in comparison with other groups. These results were in agreement with Sikarwar et al. [23] who found that, there was decrease in serum sodium in patients with decompensated cirrhosis in comparison with compensated cirrhosis mostly due to dilutional hyponatremia. Also, Gines and Guevara [24] reported that, low serum sodium levels are very common finding in patients with hepatorenal syndrome.

Regarding 24 hours urinary sodium of patients in GI and GII, there was a statistical high significant difference between the two groups. There was a significant decrease in 24 hours urinary $\mathrm{Na}$ in cirrhotic patients with massive ascites and patients with hepatorenal syndrome in comparison with 
other groups. Also, there was a statistical significant difference between cirrhotic patients without ascites and cirrhotic patients with mild to moderate ascites. This was in agreement with Kenawi et al. [25] who reported that, the urine sodium excretion in patients with chronic liver disease decreases with progression of disease and also with Fouad et al. [20] who reported that, urinary sodium excretion decrease in patients with hepatorenal syndrome. Sikarwar et al. [23] detected that, the mean urinary sodium concentration was significantly higher in cirrhotic patients without ascites than in cirrhotic patients with ascites and it was also higher in cirrhotic patients with ascites than in patients with hepatorenal syndrome.

In this study, the mean renal resistive index was significantly higher in all cirrhotic patients groups (GI and GIIa,b,c) than in control group. This result was in agreement with Cazzaniga et al. [26], Ustundag et al. [27] and Fouad et al. [20] who showed that, intra-renal RI was significantly higher in patients with cirrhosis than in healthy subjects. Also Masahiko et al. [28] demonstrated that, resistive index was significantly higher in cirrhotic patients compared to controls and compared to patients with chronic hepatitis.

Abuelo [29] reported that, the increase in renal vascular RI in cirrhotic patients with ascites can be explained by a physiological homeostatic response to vascular under filling occurring in ascitic patients. When the vascular under filling is moderate, the renal vasoactive substances are effectively counterbalanced by increased renal synthesis of prostaglandins so that, renal blood flow and GFR remain normal. In contrast, when the vascular under filling is severe, intense stimulation of endogenous vasoconstrictor systems occurs, producing renal vasoconstriction and impairment of renal blood flow and GFR. Colle et al. [30] reported that, intra-renal blood flow is preserved in cirrhotic patients by intra-renal mechanisms until the ascites becomes refractory. When this regulation fails renal ischemia causes tubular necrosis, azotemia and oliguric renal failure.

In the current study, there was a statistical high significant increase in mean renal resistive index of both kidneys in patients with massive ascites and patients with hepatorenal syndrome in comparison with other groups. On the other hand, there was no statistical significant difference between cirrhotic patients without ascites and cirrhotic patients with mild to moderate ascites.
These results were in agreement with Maroto et al. [31] who demonstrated that, RI was significantly higher in decompensated cirrhotic patients with ascites than in compensated cirrhotic patients and that the RI of compensated cirrhotic patients is higher than in the controls. They reported that, these results were highly sensitive and specific for the diagnosis of HRS. Also, in another study, Bardi et al. [31] reported that, patients with HRS had significantly higher values of RI than those without HRS. The relative risk of developing HRS in patients with an $R I=0.70$ was high. $R I$ is a useful indicator in patients with cirrhosis and ascites for the diagnosis and prognosis of HRS.

In this study, there was a statistical high significant difference between the cirrhotic patients without ascites and cirrhotic patients with ascites regarding Child classification. Most patients in GI were child A, on the other hand, the majority of patients in GII were Child C. There was a statistical high significant positive correlation between renal resistive index and child classification. This result was in agreement with the study done by Yan and Zhang [33] and Moustafa et al. [34] who detected that, there was positive correlation between RI and Child-Pugh classification. Moreover, Child C patients had the highest RI followed by Child B patients and lastly Child A patients.

In this study, there was a statistical high significant positive correlation between renal resistive index and age and total bilirubin and there was a statistical high significant negative correlation between renal resistive index and serum albumin, prothrombin concentration and platelets count. This result agreed with Abdel-Bary et al. [35] who detected that, RI had a significant positive correlation with age and total bilirubin $(\mathrm{r}=0.593$, $\mathrm{P}<0.001)$ and there was a significant negative correlation between renal RI and prothromin concentration and serum albumin $\left(\mathrm{r}={ }_{0} 0.407\right.$, $\mathrm{P}<0.001$ ) (35).This result disagreed with Moustafa et al. [34] who reported that, there was no significant correlation between renal RI and serum albumin.

Regarding the correlation between renal resistive index and serum sodium there was a statistical high significant negative correlation between them ( $\mathrm{p}$ value $<0.001$ ). In agreement with this result Abdel-Bary et al. [35] who reported that, there was negative correlation between RI and serum sodium $(\mathrm{r}=-0.341, \mathrm{P}$ value $<0.001)$. 
This study showed a highly significant positive correlation between renal resistive index and blood urea $\&$ serum creatinine. This result agreed with Sikarwar et al. [23] who reported that, there was positive correlation between the values of RI and blood Urea and serum creatinine. It was observed that, increased renal RI value in cirrhotic patients was associated with corresponding increase in blood urea level and serum creatinine. This is in contrast to Pompili et al. [36] who reported that, there was no significant correlation between renal RI and serum creatinine.

In this study, there was a statistical high significant positive correlation between renal resistive index and MELD ( $\mathrm{r}=0.739$, $\mathrm{p}$ value < $0.001)$ and MELD-Na scores $(r=0.807, \mathrm{p}$ value $<0.001)$. Theses results agreed with Abdel-Bary et al. [35] who detected that, there was a significant positive correlation between RI and MELD $(r=0.859, \mathrm{P}<0.001)$ and MELD Na $(r=$ 0.769, $\mathrm{P}<0.001$ ) (35). Patients with high MELD score had higher RI. These results also were in agreement with those of Umbro et al. [37] and Moustafa et al. [34]

In this study, Resistive index ROC curve analysis showed that, RI had AUROC $=0.997$ and if the Cutoff point of renal RI was 0.71 , the sensitivity of the test was $100 \%$, the specificity was $80 \%$, PPV was $44 \%$, NPV was $100 \%$ and accuracy was $82 \%$. The results of this study were close to that reported by Abdel-Bary et al. [35] who stated that, RI ROC curve analysis showed that RI had AUROC $=0.903$ (95\% CI: $0.835-0.949$ and $\mathrm{P}<0.001)$. At a cutoff value of RI $>0.73$, renal resistive index had sensitivity of $100 \%$ and specificity of $66.36 \%$ (35).

\section{CONCLUSION}

From the present study, we conclude that, renal duplex Doppler ultrasound is useful as a noninvasive method for the evaluation of the renal hemodynamic changes in cirrhotic patients with good correlation to the severity of liver disease. The RI may help identify a subgroup of high-risk patients with a poor prognosis that require special therapeutic care.

\section{Funding: None.}

Conflicts of interest: None.

Ethical approval:Approved.

\section{REFERENCES}

1. Bell H, Jahnsen J, Kittang E Raknerud $\mathrm{N}$ and Sandvik L et al. Long-term prognosis of patients with alcoholic liver cirrhosis: A 15 -years followup study of 100 Norwegian patients admitted to one unit. Scand J Gastroenterol 2004; 9: 858- 863.

2. Gines $P$ and Schrier RW: Renal failure in cirrhosis. N Engl J Med 2009; 361:1279.

3. Wadei HM, Mai ML, Ahsan N and Gonwa TAet al. Hepatorenal syndrome: Pathophysiology and management. Clin J Am Soc Nephrol 2006; 1: 1066.

4. Ross S, Thometz D, Serafini F, Bloomston M, Morton C, Zervos E et al. Renal haemodynamics and function following partial portal decompression. HPB (Oxford) 2009; 11(3):229-34.

5. Lata J: Hepatorenal syndrome. World J Gastroenterology 2012; 18(36): 4978-84. .

6- Sherman DS, Fish DN and Teitebaum I: Assessing renal function in cirrhotic patients: problems and pitfalls. Am J Kidney Dis 2003; 41: 269-78.

7. Berzigotti A, Casadei A, Magalotti D, Castaldini N, Losinno F, Rossi C et al. Renovascular impedance correlates with portal pressure in patients with liver cirrhosis. Radiology 2006; 240: 581 - 586.

8. Rademacher J, Mengel M, Ellis S, Stuht S, Hiss M, Schwarz A et al. The renal arterial resistance Index and renal allograft survival. New Engl J Med 2003; 349: 115- 124.

9. Kastelan S, Ljublcic N, Kastelan Z and Uravic M. The role of duplex Doppler ultrasonography in the diagnosis of renal dysfunction and hepatorenal syndrome in patients with liver cirrhosis. Hepatogastroenterology 2004; 51: 1408-1412.

10. Catherine PC, Eric MG and Sanjiv C: Cirrhosis and portal hypertension; In: Lawrence SF, Jules LD and Emmet BK editors. Handbook of liver disease, $3^{\text {rd }}$ edition 2012; Saunders, an imprint of Elsevier Inc. pp:138-143.

11. Kamath PS, Wiesner RH, Malinchoc M, Kremers W, Therneau TM, Kosberg CL et al. A model to predict survival in patients with end-stage liver disease. Hepatology 2001; 33(2):464-70.

12. Kim WR, Biggins SW, Kremers WK, Wiesner RH, Kamath PS, Benson JT et al. Hyponatremia and mortality among patients on the liver-transplant waiting list. N Engl J Med 2008; 359(10):1018-26.

13. Salerno F, Gerbes A, Gine`s P, Wong F and Arroyo V. Diagnosis, prevention and treatment of hepatorenal syndrome in cirrhosis. Gut 2007; 56:1310-1318.

14. Tublin ME, Bude RO and Platt JF: Resistive Index in Renal Doppler Sonography: Where Do We Stand? AJR 2003; 180:885-892.

15. Platt J, Ellis J and Rubin J: Examination of Native Kidneys with Duplex Doppler Ultrasound. Semin Ultrasound CT MR 1991; 12:308-318. 
16. Lozano R, Naghavi M, Foreman K and Memish Z. Global and regional mortality from 235 causes of death for 20 age groups in 1990 and 2010: a systematic analysis for the Global Burden of Disease Study 2010. Lancet 2012; 380: 2095-128.

17. Angeli $\mathrm{P}$, Wong $\mathrm{F}$, Watson $\mathrm{H}$ and Gin'es. Hyponatremia in cirrhosis: Results of a patient population survey. Hepatology 2006; 44:15351542.

18. Zeller T, Bonvini RF and Sixt S: Color-coded duplex ultrasound for diagnosis of renal artery stenosis and as follow-up examination after revascularization. Catheter Cardiovasc Interv 2008; 71: 995-9.

19. Goyal S, Dixit VK, Jain AK, Shukla RC, Ghosh and Kumar V. Intrarenal resistance index (RI) as a predictor of early renal impairment in patients with liver cirrhosis. Tropical Gastroenterology 2013; 34(4):235-23.

20. Fouad YM, Mokarrab H, Elgebaly AF, El Amin H, Abdel Raheem E, Sharawy MA et al. Renal duplex Doppler ultrasound in patients with $\mathrm{HCV}$ related liver cirrhosis. Trop Gastroenterol 2009; 30(4):213-8.

21. Amer FA, Gohar M and Yousef M: Epidemiology of Hepatitis C Virus Infection in Egypt. International Journal of Tropical disease \& Health 2015; 7(3):119-131.

22. Nix DE, Erstad BL, Nakazato PZ and Krueger TS. Estimation of creatinine clearance in end-stage liver disease. Ann Pharmacother 2006; 40:900-8.

23. Sikarwar J, Muchhoria S, Singh R, Bhujade H and Ahirwar V. Study of Resistive Index in various stages of Liver Cirrhosis and its significance in Calculating the Risk for Hepatorenal Syndrome. Journal of Evolution of Medical and Dental Sciences 2014; 3(5): 1195-1205.

24. Gines P and Guevara M: Hyponatremia in Cirrhosis: Pathogenesis, Clinical Significance, and Management. Hepatology 2008; 48 (3):1002-1010.

25. Kenawi AM, Hamid AA and Sahar AA: Renal resistive index and sodium concentration as a predictor of renal dysfunction in patients with advanced liver cirrhosis. MD thesis 2004, Cairo University.

26. Cazzaniga M, Salerno F, Visentin S, Cirello I, Donarini $\mathrm{C}$ and Cugno M. Increased flow mediated vasodilation in cirrhotic patients with ascites: relationship with renal resistive index. Liver Int 2008; 28(10):1396-401.

27- Ustundag Y, Hekimog` lu K, Ilikhan S et al. Serum glucagon and cystatin $\mathrm{C}$ levels with renal
Doppler sonography findings in nonazotemic liver cirrhosis cases. Hepatogastroenterology 2011; 58:926-31.

28. Masahiko K, Murawaki $\mathrm{Y}$ and Kawasaki H: Renovascular resistance assessed by color Doppler ultrasonography in patients with chronic liver diseases. Western Pacific Helicobacter Congress No 3, Pasar, Bali, Indonesie 2000; 15(12):1424-1429.

29. Abuelo GJ: Diagnosing vascular causes of renal failure. Ann Intern Med 1995; 123:601-14.

30. Colle I, Moreau R, Pessione F, Rassiat E, Heller J, Chagneau $\mathrm{C}$ et al. Relationship between haemodynamic alternations and the development of ascites or refractory ascites in patients with cirrhosis. Eur J Gastroentrol Hepatol 2001; 13: 251-6.

31. Maroto A, Ginès A, Saló J, Clària J, Ginès $\mathrm{P}$, Anibarro L et al. Diagnosis of functional renal failure of cirrhosis with Doppler sonography: prognostic value of resistive index. Hepatology 1994; 20:839-44.

32. Bardi A, Sapunar J and Oksenberg D. Intrarenal arterial Doppler ultrasonography in cirrhotic patients with ascites, with and without hepatorenal syndrome. Rev Med Chil 2002; 130:173-80.

33. Yan Y and Zhang BL: Clinical study of renal blood flow and endothelin in cirrhotic patients. Zhonghua Gan Zang Bing Za Zhi 2004; 12(5):278-80.

34. Moustafa M, Eid A, Hassan M and Ahmed AA. Evaluating the effect of midodrine on renal resistance index in patients with liver cirrhosis and ascites. Al Azhar Assiut Medical Journal 2016; 14:19-23.

35. Abdel-Bary SA, Safwat E, Hussein HA, Husseinb $\mathrm{AM}$ and Botrosb SM. Value of renal resistive index in hepatitis $\mathrm{C}$ virus related liver cirrhosis and its response to midodrine. The Egypt J Radiol Nucl Med 2014; 45:1079-1087.

36. Pompili M, Rapaccini GL, De Luca F, Agnes S, Avolio AW, Covino $\mathrm{M}$ et al. Doppler ultrasonographic evaluation of the early changes in renal resistive index in cirrhotic patients undergoing liver transplantation. J Ultrasound Med 1999; 18(7):497-502.

37. Umbro I, Tinti F, Fiacco F, Zavattoa A, Pisellib P, Di Natalea $\mathrm{V}$ et al. Resistive index and MELDNa: nephrologic monitoring in cirrhotic patients awaiting liver transplantation. Transplant Proc 2013; 45:2676-2679. 